Article

\title{
Acetoacetate Based Thermosets Prepared by Dual-Michael Addition Reactions
}

\author{
Osman Konuray ${ }^{1, *(\mathbb{D})}$, Xavier Fernández-Francos ${ }^{1}$, Xavier Ramis ${ }^{1}$ (D) and Àngels Serra ${ }^{2}$ (D) \\ 1 Thermodynamics Laboratory, ETSEIB, Universitat Politècnica de Catalunya, Av. Diagonal 647, \\ 08028 Barcelona, Spain \\ 2 Department of Analytical and Organic Chemistry, Universitat Rovira i Virgili, C/Marcel lí Domingo s/n, \\ 43007 Tarragona, Spain \\ * Correspondence: osman.konuray@mmt.upc.edu
}

Received: 13 May 2019; Accepted: 1 August 2019; Published: 27 August 2019

check for updates

\begin{abstract}
A novel set of dual-curable multiacetoacetate-multiacrylate-divinyl sulfone ternary materials with versatile and manipulable properties are presented. In contrast to common dual-curing systems, the first stage polymer herein consists of a densely crosslinked, high $T_{g}$ network as a result of base-catalyzed multiacetoacetate-divinyl sulfone Michael addition. A more flexible secondary network forms after base-catalyzed Michael addition of remaining multiacetoacetate to multiacrylate. Curing is truly sequential as the rates of the two Michael additions are significantly different. Curing kinetics were analyzed using differential scanning calorimetry (DSC) and Fourier-transform infrared (FTIR). The materials at each curing stage were characterized using dynamic mechanical analysis (DMA) and SEM. Although some phase separation was observed in certain formulations, the incompatibilities were minimized when the molar percentage of the acetoacetate-divinyl sulfone polymer network was above $75 \%$. Furthermore, the environmental scanning electron microscopy (ESEM) images of these materials show that the more flexible acetoacetate-acrylate phase is dispersed in the form of polymeric spheres within the rigid acetoacetate-divinyl sulfone matrix. This unique dual microstructure can potentially render these materials highly resilient in applications requiring densely crosslinked polymer architectures with enhanced toughness.
\end{abstract}

Keywords: dual-curing; Michael addition; click chemistry; acetoacetate; divinyl sulfone; acrylate

\section{Introduction}

Recently, more and more thermosetting polymers are prepared by versatile dual-curing methodologies due to their many advantages in terms of material processing [1-5]. A dual-curing process is a combination of two compatible and selective polymerizations carried out either simultaneously or sequentially. In contrast, for simultaneous dual-curing, a sequential process facilitates processing flexibility as it affords the storage of stable intermediate (i.e., partially-cured) materials. The properties of these intermediate materials can easily be tailored a priori by careful selection of monomers and their proportions. As a result, they can range from liquid-like adhesives to semi-rigid and conformable solids [6]. The second curing stage is initiated at a later time using a different stimulus to yield the final material with significantly improved mechanical properties.

Click chemistry is an effective tool in designing efficient and environmentally safe dual-curing processes [1,7-9]. Among the numerous click polymerization reactions, Michael additions are arguably the most common reaction type in recent dual-curing systems [10-13]. A Michael addition is described as the conjugate addition of nucleophilic carbanions to activated double bonds [10]. The reaction can be initiated by basic or nucleophilic catalysts. A variety of nucleophiles (Michael donors) and activated double bond compounds (Michael acceptors) are commercially available. In Michael-type dual curing 
systems, the Michael donor is more frequently a thiol [3,11,12,14], or an amine [4,15-17] Acetoacetates are also employed, but less frequently [18-20]. As a matter of fact, acetoacetates introduce many advantages to dual-curing systems. Their Michael reaction kinetics are slower compared to other donors therefore no premature curing takes places during sample preparation. Their polymers have a high crosslink density and superior mechanical properties especially if monomeric acetoacetates have high functionalities. Consequently, acetoacetate functional monomers are used in different applications, such as low energy curing coatings and adhesives [10,21,22].

Since it is a novelty on its own, this paper starts with a preliminary kinetic analysis of the acetoacetate-divinyl sulfone Michael addition. Although the general Michael addition mechanism is well documented, this particular Michael donor-acceptor pair has not been studied before. After establishing the conditions for this reaction, this study prepared a set of dual curable multiacetoacetate-multiacrylate-divinyl sulfone ternary formulations with versatile and manipulable properties. Depending on the initial monomer mixture, (after a first curing stage) liquid or solid intermediate materials can be obtained which can be used immediately in the application or can be transported and/or stored for prolonged periods. This processing flexibility can be desirable for demanding applications. In contrast to common dual-curing systems, the first stage polymer herein consists of a densely crosslinked, high $T_{g}$ network as a result of the base-catalyzed multiacetoacetate-divinyl sulfone Michael addition. A more flexible secondary network forms after a base-catalyzed Michael addition of remaining multiacetoacetate to multiacrylate. This is not surprising as it was reported by other researchers that, compared to acrylic monomers, vinyl sulfone based monomers yield high $T_{g}$ materials due to structural effects, $\pi$-electronic and dipolar interactions and hydrogen bonding [23]. To obtain a truly sequential curing process, the authors took advantage of the intrinsic difference of the Michael reaction kinetics of acrylates and vinyl sulfones. This bestows selectivity to the acetoacetate-vinyl sulfone reaction in any mixture in which acrylate groups are also present, as was documented in the past $[12,24,25]$. A phase separation is observed in these materials induced by the polymerization process. However, the study shows that the extent of the incompatibilization can be controlled by changing the monomer feed ratio. The microstructure of the resulting dual-network materials suggests that the second stage multiacetate-multiacrylate network might potentially act as a toughness enhancer.

\section{Materials and Methods}

A trifunctional acetoacetate K-FLEX ${ }^{\circledR} 7301$ (hereafter referred to as KF, equivalent weight per active hydrogen of $125 \mathrm{~g} / \mathrm{e}$ according to the data sheet), supplied by King Industries, Norwalk, CT, USA, was used as a Michael reagent donor. Michael acceptors, divinyl sulfone (DVS, $118.15 \mathrm{~g} / \mathrm{mol}$ ) and hexanediol diacrylate (HDDA, $226.27 \mathrm{~g} \cdot \mathrm{mol}^{-1}$ ), supplied by Sigma Aldrich, Saint Louis, MO, were used without any purification. The catalyst 1-methylimidazole (1-MI), a weak base, was also supplied by Sigma Aldrich and was used without purification. The structures of all chemicals used are given in Table 1.

Table 1. Monomers and the catalyst used in the work.

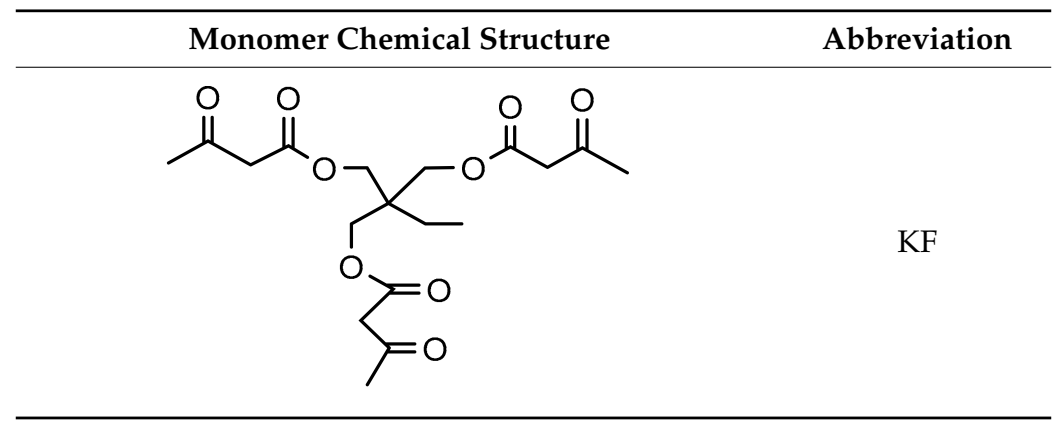


Table 1. Cont.

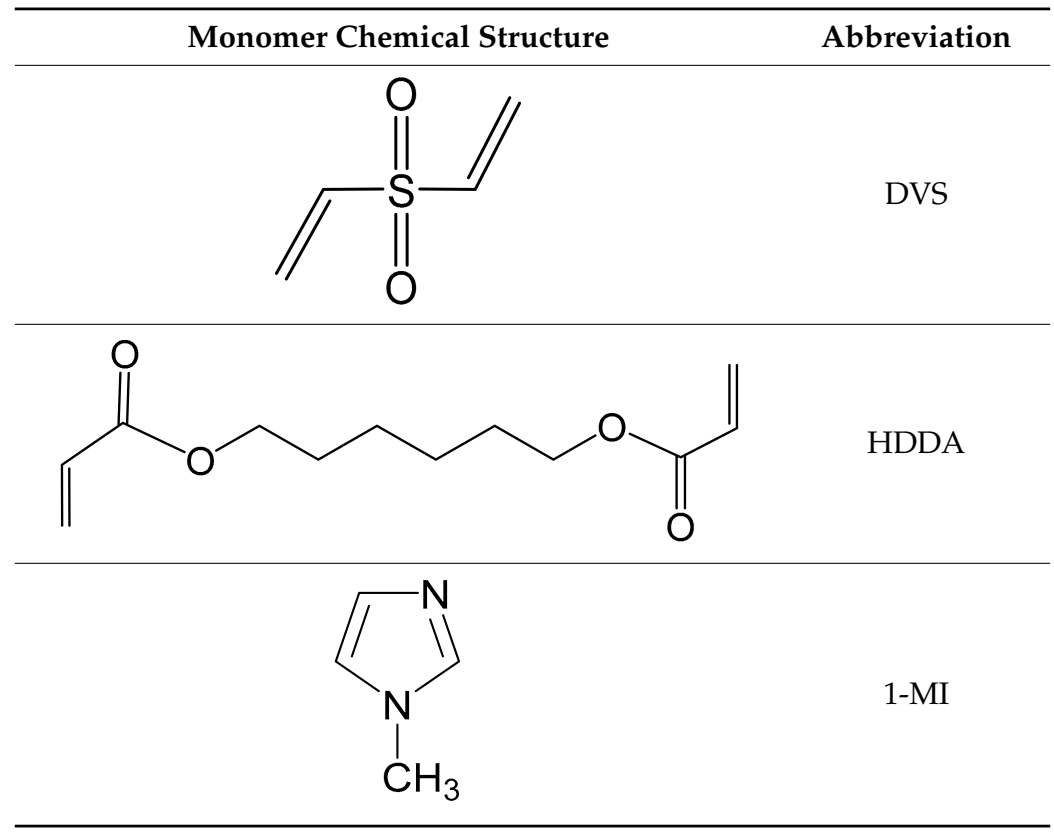

The stoichiometric KF-DVS formulations with 2 phr of $1 \mathrm{MI}$ were prepared, assuming that the functionality $(f)$ of KF was 6 or 3 . The stoichiometric dual formulations containing different KF:DVS:HDDA ratios were also prepared, but it was assumed that $f=6$. The dual-curing process is depicted in Scheme 1. The notation and composition of the different dual formulations are shown in Table 2.

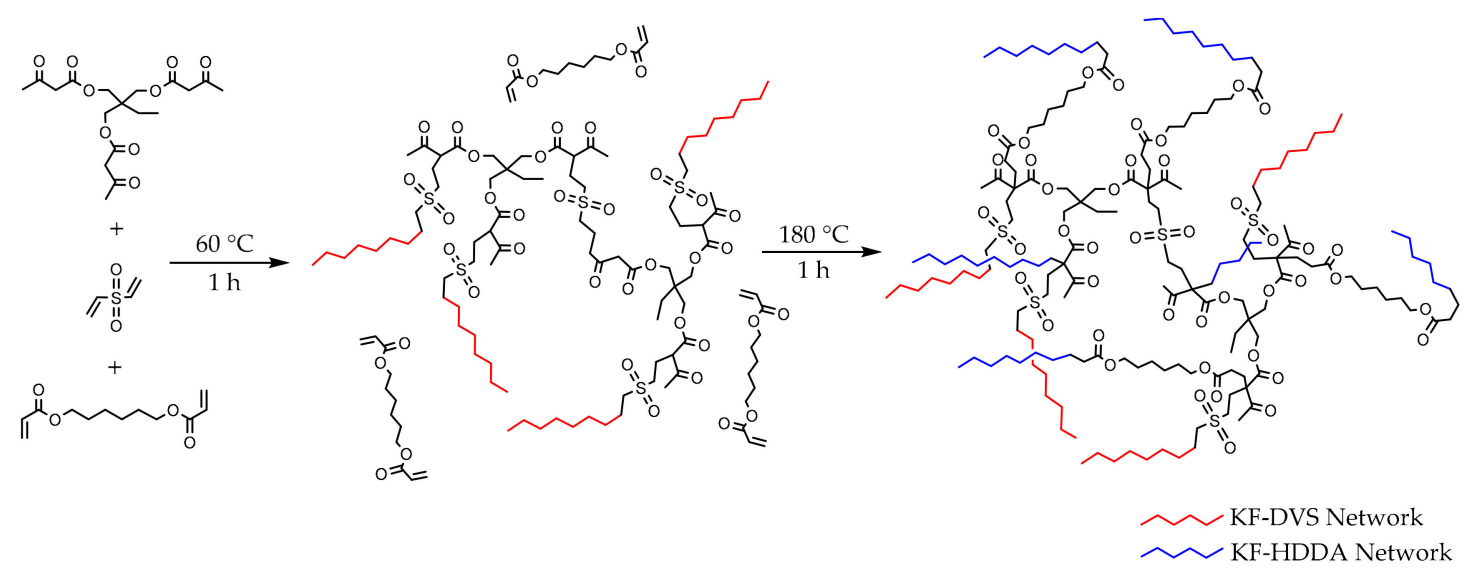

Scheme 1. The curing process used to produce the KF- divinyl sulfone (DVS)- hexanediol diacrylate (HDDA) dual network.

Table 2. The composition of the dual-curing formulations prepared for the study, assuming $f=6$ for the acetoacetate KF.

\begin{tabular}{lccccc}
\hline \multirow{2}{*}{ Formulation } & \multirow{2}{*}{$\begin{array}{c}\text { KF:DVS:HDDA } \\
\text { Molar Ratio }\end{array}$} & \multicolumn{5}{c}{ Weight Fractions } \\
\cline { 3 - 6 } & & KF & DVS & HDDA & 1-MI \\
\hline DVS-HDDA 1-0 & $1: 1: 0$ & 0.51 & 0.49 & 0 & 0.02 \\
\hline DVS-HDDA 3-1 & $4: 3: 1$ & 0.46 & 0.33 & 0.21 & 0.02 \\
\hline DVS-HDDA 1-1 & $2: 1: 1$ & 0.42 & 0.20 & 0.38 & 0.02 \\
\hline DVS-HDDA 1-3 & $4: 1: 3$ & 0.39 & 0.09 & 0.52 & 0.02 \\
\hline DVS-HDDA 0-1 & $1: 0: 1$ & 0.36 & 0 & 0.64 & 0.02 \\
\hline
\end{tabular}


In the preliminary analysis of the KF-DVS reaction kinetics, differential scanning calorimetry (DSC) was performed under isothermal conditions and by selecting adequate temperatures. The runs were continued until no further heat release was observed and the maximal double bond conversions $(x)$ were calculated using Equation (1).

$$
x=1-\frac{\Delta H_{\text {residual }}}{\Delta H_{\text {total }}}
$$

where $\Delta H_{\text {total }}$ was determined in a dynamic scan from 30 to $250{ }^{\circ} \mathrm{C}$ at a heating rate of $10{ }^{\circ} \mathrm{C} / \mathrm{min}$. The glass transition temperatures, $T_{g}$, of the samples were determined as the halfway point in the heat capacity step during a dynamic DSC scan at $10^{\circ} \mathrm{C} \mathrm{min}^{-1}$. In order to model the dependence of the $T_{g}$ on the degree of conversion, $T_{g}(x)$, the expression derived by Venditti and Gillham [26] has been used:

$$
\begin{gathered}
\ln T_{g}(x)=\frac{(1-x) \cdot \ln T_{g 0}+\lambda \cdot x \cdot \ln T_{g \infty}}{(1-x)+\lambda \cdot x} \\
\lambda=\frac{\Delta C_{p \infty}}{\Delta C_{p 0}}
\end{gathered}
$$

where $T_{g 0}$ and $T_{g \infty}$ are the glass transition temperatures (in $\mathrm{K}$ ) of the uncured and crosslinked materials, and $\Delta C_{p 0}$ and $\Delta C_{p \infty}$ are the increase in heat capacity during the glass transition of the uncured and crosslinked materials, respectively, measured in the same DSC experiment.

To further study the curing kinetics, a Brucker Vertex 70 Fourier-transform infrared (FTIR) spectrometer equipped with an attenuated total refection (ATR) accessory (Golden gateTM, Specac Ltd., Orpington, UK) which is temperature controlled (heated single-reflection diamond ATR crystal) was used to monitor the evolution of the reactive groups. Real-time spectra were collected at the chosen curing temperatures in absorbance mode with a resolution of $4 \mathrm{~cm}^{-1}$ and a wavelength range from 400 to $4000 \mathrm{~cm}^{-1}$, averaging 20 scans for each spectrum. The bands at 700 and $775 \mathrm{~cm}^{-1}$ [24] were used to monitor the evolution of vinyl sulfone double bonds, whereas the band at $810 \mathrm{~cm}^{-1}$ [27] was used to monitor acrylate double bonds disappearance. The peaks were normalized using the carbonyl ester band at $1720 \mathrm{~cm}^{-1}$ [28]. The conversion of double bonds is denoted as $x$ and it is defined by Equation (4).

$$
x=1-\frac{A_{t}^{\prime}}{A_{0}^{\prime}}
$$

where $A^{\prime}$ is the normalized area of the acrylate or vinyl sulfone bands, and the subscripts $t$ and 0 indicate the curing time and the beginning of the curing, respectively.

Final materials, along with intermediate materials which could be obtained in solid form, were analyzed using a dynamic mechanical analysis (DMA). A TA Instruments DMA Q800 device was used. The test specimens were prepared by pouring the liquid monomer mixtures in prismatic molds of dimensions ca. $1 \times 13 \times 20 \mathrm{~mm}^{3}$ and oven curing: $1 \mathrm{~h}$ at $60{ }^{\circ} \mathrm{C}$ (curing stage 1 , KF-DVS reaction) followed by $1 \mathrm{~h}$ at $180^{\circ} \mathrm{C}$ (curing stage 2, KF-HDDA reaction), and a $30 \mathrm{~min}$. postcuring at $200^{\circ} \mathrm{C}$ to ensure complete conversion. The choice of curing temperatures is based on the kinetic analyses which is explained in the following sections. The prepared specimens were analyzed using a single cantilever clamp at a frequency of $1 \mathrm{~Hz}$ and $0.05 \%$ strain at $3{ }^{\circ} \mathrm{C} / \mathrm{min}$ within adequately chosen temperature ranges to observe a complete network relaxation of each sample. The peak temperatures of $\tan \delta$ curves were taken as $\alpha$-relaxation temperatures. The peak temperatures of loss moduli curves were taken as approximation of thermal $T_{g}$.

Thermogravimetric analysis (TGA) was carried out with a Mettler TGA/SDTA 851e/LF/1100 thermobalance. The fully cured samples with an approximate mass of $10 \mathrm{mg}$ were thermally degraded between 30 and $800^{\circ} \mathrm{C}$ at a heating rate of $10^{\circ} \mathrm{C} / \mathrm{min}$ in a nitrogen atmosphere $\left(50 \mathrm{~cm}^{3} / \mathrm{min}\right.$ measured under normal conditions). 
The environmental scanning electron microscopy (ESEM) was used to examine the fracture surfaces of the materials prepared. A Quanta 600 environmental scanning electron microscopy (FEI Company, Hillsboro, Oregon, USA) allowed collecting micrographs at $10-20 \mathrm{kV}$ and at a low vacuum mode without the need to coat the samples.

\section{Results and Discussion}

\subsection{KF-DVS Pure System (Stage 1)}

Firstly, the neat multiacetoacetate (KF)-divinyl sulfone (DVS) system (DVS-HDDA 1-0) was characterized with respect to reaction kinetics. The choice of a KF-DVS molar ratio depends on the desired effective functionality $(f)$ of KF. If only the primary acetoacetate hydrogens are assumed to undergo a Michael addition, functionality is $3(f=3)$. Whereas if both primary and secondary acetoacetate hydrogens are assumed to react, functionality becomes $6(f=6)$. Preliminarily, both cases were tested. DVS-HDDA 1-0 formulations were prepared and a Michael addition carried out at 35 and $80^{\circ} \mathrm{C}$ in the presence of $0.5 \%(w / w)$ of 1-methylimidazole (1-MI). In Table 3, the final conversions reached in isothermal conditions (calculated using Equation (1)) and the time to reach these conversions are given with regard to assumed functionalities.

Table 3. The maximum vinyl differential scanning calorimetry (DSC) conversions ( $x$ ) achieved in KF-DVS Michael addition at different reaction temperatures $(T)$. The reactions were catalyzed by $0.5 \%$ $(w / w)$ 1-MI. ${ }^{a}$ KF:DVS molar ratio was $0.68: 0.32,{ }^{b}$ KF:DVS molar ratio was $0.52: 0.48,{ }^{\mathrm{c}}$ Time to reach a conversion plateau.

\begin{tabular}{cccc}
\hline Functionality & $\boldsymbol{T}\left({ }^{\circ} \mathbf{C}\right)$ & $\boldsymbol{x}(\boldsymbol{\%})$ & $\mathbf{t}(\mathbf{m i n})^{\mathbf{c}}$ \\
\hline \multirow{2}{*}{$3^{\mathrm{a}}$} & 35 & 92 & 300 \\
\cline { 2 - 4 } & 80 & 98 & 180 \\
\hline \multirow{2}{*}{$6^{\mathrm{b}}$} & 35 & 77 & 240 \\
\hline & 80 & 90 & 90 \\
\hline
\end{tabular}

In Figure 1, the accuracy of the Venditti and Gillham approximation for the $T_{g}-x$ relationship is demonstrated. The thermal parameters determined by DSC and used in the Equation (2) are tabulated in Table 4. As can be seen, vitrification and therefore incomplete conversion took place in all the experiments with $f=6$ because $T_{g \infty}$ was higher than the curing temperature. For $f=3$, vitrification was only observed at the curing temperature of $35^{\circ} \mathrm{C}$, and conversion at $80^{\circ} \mathrm{C}$ was not complete because of the slow reaction kinetics at the end of the curing process. Higher conversions were achieved when $f=3$ due to the lower value of $T_{g \infty}$ (see Table 4). In contrast, for $f=6$, the lower conversion is achieved because of the significantly higher value of $T_{g_{\infty}}$. The low value of $\lambda$ for $f=6$ (Table 4 ) is an indication of the significant reduction in mobility that takes place during the crosslinking process because of the densely crosslinked structure that is being formed, but at the same time it implies that $T_{g}$ is a weak function of $x$ up to high values of $x$. As a result, even for $f=6$, vitrification is not a significant impediment to reach high conversions. In the light of these findings, $f$ was fixed at 6 for the dual formulations prepared in the rest of the study. Furthermore, the Stage 1 curing temperature was chosen as $60^{\circ} \mathrm{C}$. As is shown later, within the dual formulation, the KF-DVS reaction proceeds to completion in $1 \mathrm{~h}$ at this temperature since dilution by the KF-HDDA part overcomes any mobility restriction. 


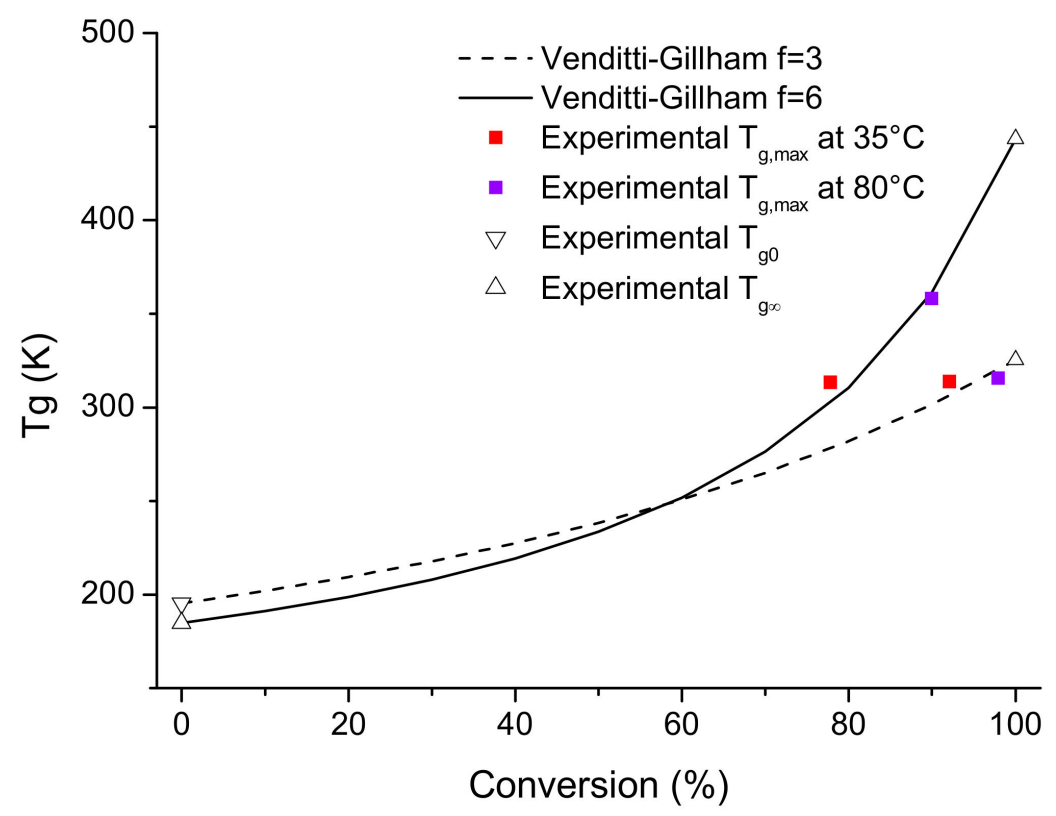

Figure 1. The relationship between $T_{g}$ and conversion for the KF-DVS pure system (DVS-HDDA 1-0). Experimental $T_{g}$ were determined by DSC. $T_{g 0}$ and $T_{g \infty}$ were used to construct the Venditti-Gillham curves. The experimentally determined maximal $T_{g}$ of formulations with different acetoacetate functionalities (colored squares) fit well to their corresponding curves.

Table 4. DSC determined parameters of DVS-HDDA 1-0 used to construct the Venditti-Gillham curves (Equation (2)).

\begin{tabular}{ccc}
\hline$f$ & $\mathbf{3}$ & $\mathbf{6}$ \\
\hline$T_{g 0}(\mathrm{~K})$ & 195.2 & 184.8 \\
$T_{g \infty}(\mathrm{K})$ & 325.3 & 443.4 \\
$\Delta C_{p 0}(\mathrm{~J} / \mathrm{g} \cdot \mathrm{K})$ & 0.619 & 0.666 \\
$\Delta C_{p \infty}(\mathrm{J} / \mathrm{g} \cdot \mathrm{K})$ & 0.396 & 0.243 \\
$\lambda$ & 0.640 & 0.365 \\
\hline
\end{tabular}

\subsection{Dual System KF-DVS-HDDA (2:1:1 Molar Ratio)}

To study the overall curing kinetics, the formulation DVS-HDDA 1-1 was chosen. FTIR was used to follow the evolution of the different species during both stages. Within the dual formulation, the first stage KF-DVS curing reaction virtually consumes all DVS monomers, in contrast with the pure KF-DVS system, even at a lower temperature (see Figure 2). As postulated previously, the KF excess and HDDA provide the convenient dilution to overcome mobility restrictions posed during the formation of the KF-DVS network. No acrylate reaction was observed in this first curing stage, as could be expected, given the better Michael acceptor character of the vinylsulfone groups in comparison with acrylate groups [24] (see inset in Figure 2, stage 1). The second stage, the KF-HDDA curing reaction, was carried out at $180^{\circ} \mathrm{C}$, with a comparable rate to stage 1 . To ensure conversion of all monomers, a postcuring was performed for $30 \mathrm{~min}$ at $200{ }^{\circ} \mathrm{C}$. Similar kinetics were observed in all remaining formulations whose results are not shown here for space considerations. Given the selectivity in the first curing stage and the significant difference between curing temperatures at stages 1 and 2, it can be safely stated that ternary KF-DVS-HDDA formulations are truly sequential dual-curing systems. 


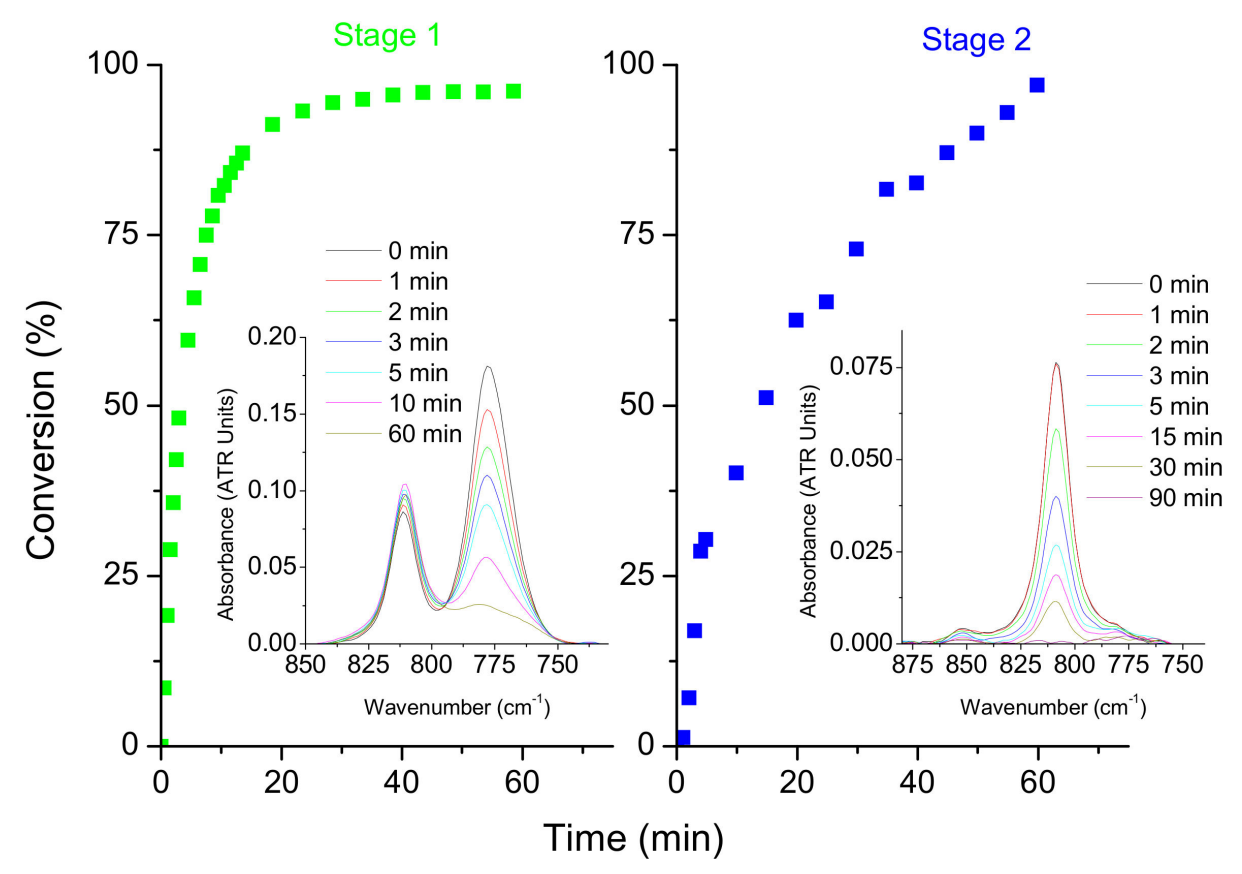

Figure 2. The Fourier-transform infrared (FTIR) double bond conversion for the dual-curing of DVS-HDDA 1-1. Note that the absorption peak at $810 \mathrm{~cm}^{-1}$ (inset figure on the left) remains intact during stage 1 , confirming the selectivity of the curing reaction. Curing temperatures are $60{ }^{\circ} \mathrm{C}$ and $180^{\circ} \mathrm{C}$ for stages 1 and 2 , respectively.

\subsection{Material Properties}

The thermal-mechanical properties of intermediate and fully-cured dual formulations were analyzed with DMA and DSC. The $\alpha$-relaxation curves of fully cured formulations determined with DMA are given in Figure 3. As can be seen, in all dual formulations, $\alpha$-relaxations become somewhat multi-modal, indicating network heterogeneity, especially for the dual-curing formulation DVS-HDDA 1-1. In fact, formulation DVS-HDDA 1-1 and DVS-HDDA 3-1 had opaque appearances, indicating phase separation, while DVS-HDDA 1-3 was transparent, indicating that the material was homogeneous. The phase separation is not perfect, as the $\tan \delta$ peaks of dual formulations did not correspond exactly to those of the constituent parts (i.e., Neat KF-DVS and KF-HDDA). Furthermore, at the end of the Stage 1 of the dual curing, the DVS-HDDA 1-1 and DVS-HDDA 3-1 materials (which are DVS-rich) had already exhibited polymerization-induced phase separation due to the incompatibility between the KF-DVS network formed during Stage 1 and the unreacted monomers (the excess KF and HDDA). This phenomenon was observed previously for epoxy-acrylic systems [29,30]. Although the acrylate-rich phase in DVS-HDDA 3-1 only produced a slightly detectable peak in its tan delta, it produced a stronger one in its loss modulus at approximately $0^{\circ} \mathrm{C}$ (See Figure 3, right-hand side inset).

The evolution of the viscoelastic properties of the DVS-HDDA-3-1 formulation is shown in Figure 4. As a matter of fact, the material can be thought of as a KF-DVS system covalently modified with $25 \%$ (by moles) of a KF-HDDA network. Since monomer HDDA had a significantly more flexible backbone in comparison to DVS, the increase in $T_{g}$ after the KF-HDDA reaction (curing stage 2) was slight. A closer look at the evolution of the loss modulus $E^{\prime \prime}$ hints at the presence of a secondary relaxation in the intermediate material at approximately $-20^{\circ} \mathrm{C}$, which disappears in the fully cured material. This suggests the presence of a second phase in the intermediate material, as discussed above. 


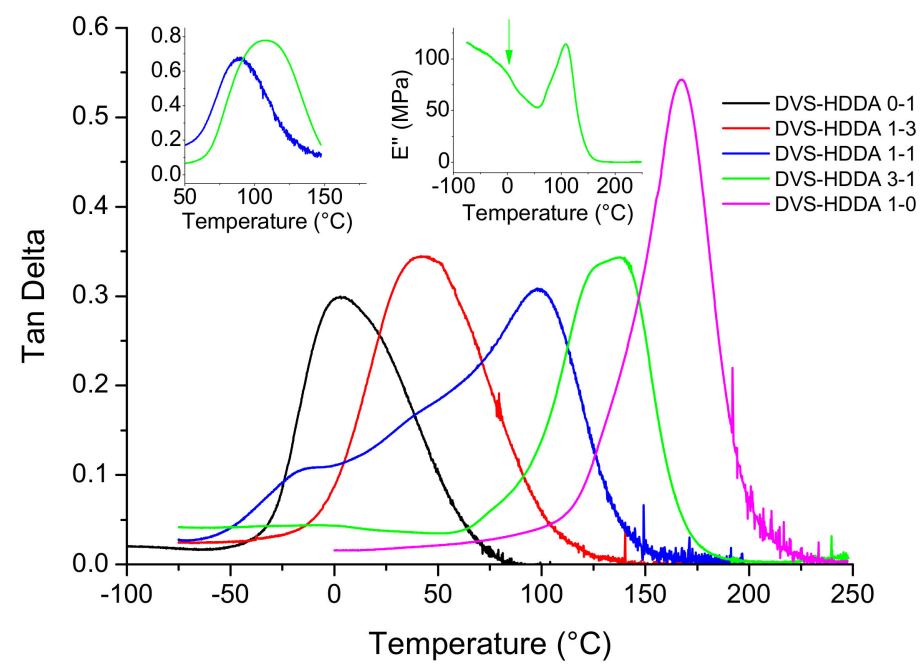

Figure 3. $\alpha$-relaxations of KF-DVS-HDDA ternary materials. The left-hand side inset shows $\alpha$-relaxation profiles of the intermediate materials which were solid and thus a dynamic mechanical analysis (DMA) analysis was possible. The loss modulus curve of DVS-HDDA 3-1 is shown in the right-hand side inset in which a stronger peak is produced by the acrylate-rich phase.

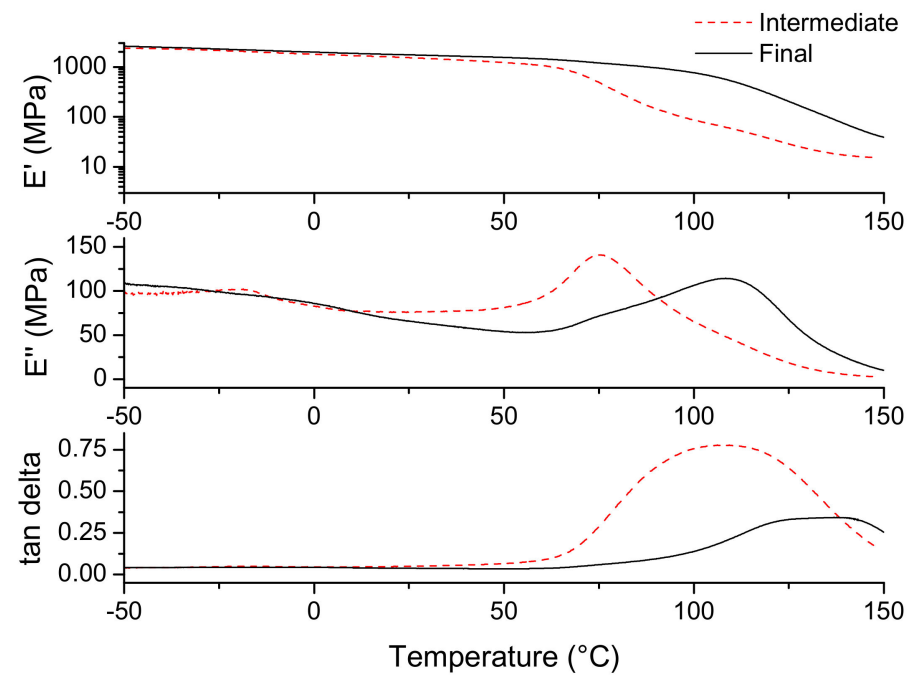

Figure 4. Storage moduli ( $\left.E^{\prime}\right)$, loss moduli ( $\left.E^{\prime \prime}\right)$ and tan $\delta$ curves of DVS-HDDA 3-1 intermediate (dashed red) and final (solid black) materials.

As further analysis, the temperatures at the maximum loss modulus which are empirically correlated to the $T_{g}$ determined by DSC were plotted together with the Fox approximations [31] as a function of DVS weight fraction. This study determined the theoretical values of the intermediate $T_{g, i n t}$ making use of the $T_{g, f}$ of the fully cured DVS-HDDA 1-0 material (see Table 4) and the $T_{g}$ of the uncured DVS-HDDA 0-1 material, which was of $-94^{\circ} \mathrm{C}$. For the final $T_{g, f}$ the $T_{g, f}$ of the fully cured DVS-HDDA 1-0 material (see Table 4) and the $T_{g}$ of the fully cured DVS-HDDA 0-1 was used, which had a value of $-17^{\circ} \mathrm{C}$. The resulting $T_{g, i n t}$ and $T_{g, f}$ graphs are given in Figure 5 . Conventionally, thermal $T_{g} S$ (obtained by DSC) of the intermediate and final dual-curing should have been compared with predictions made using the Fox approximation. However, the materials used in this study did not exhibit clear glass transitions in the DSC, possibly due to their highly heterogeneous polymer networks. At the intermediate stage, DVS-HDDA 1-1 and DVS-HDDA 3-1 had to be analyzed with DMA as they had attained a gel state, while intermediate DVS-HDDA 3-1, which was ungelled, was analyzed with DSC. The final materials were all characterized with DMA. In order to make meaningful comparisons, the values of $T_{g}$ were assigned, making use of the peaks of the loss modulus $E^{\prime \prime}$ curves, which should 
give values lower than $\tan \delta$ peak temperatures and closer to calorimetric $T_{g}$. Given the breadth of the glass transitions, in some cases, the position of the relaxation had to be assigned taking also into consideration $E^{\prime}$ and $\tan \delta$ curves.

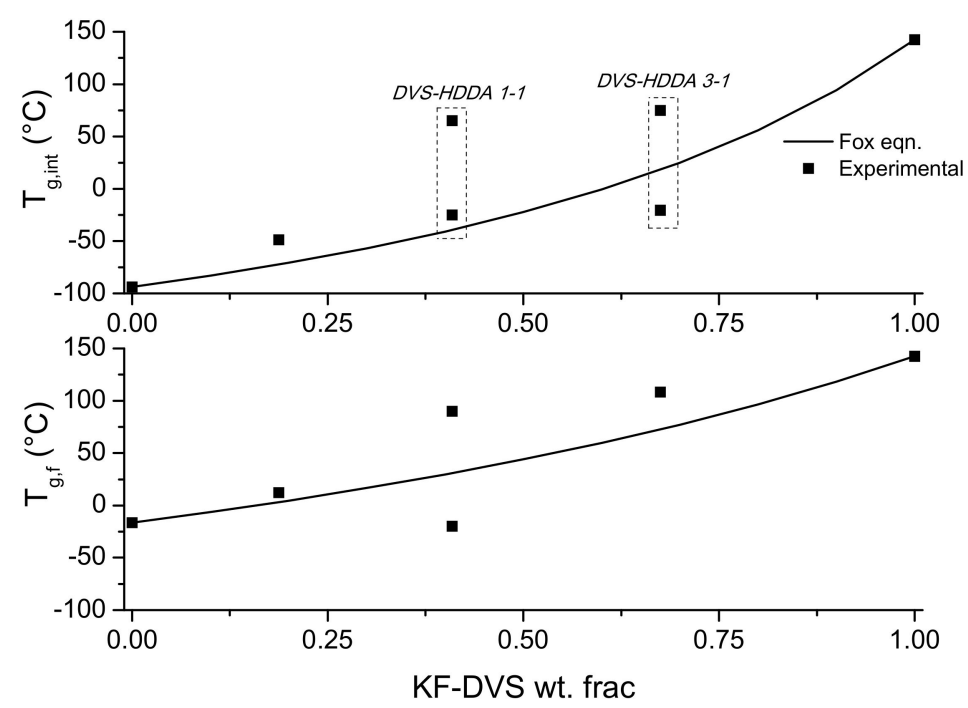

Figure 5. Intermediate (top) and final $T_{g}$ (bottom) as a function of DVS weight fraction. The curves are drawn using the Fox equation [31]. The filled squares represent experimentally determined values.

For the DVS-HDDA 1-1 material, two clearly separated E" peaks were observed at both curing stages. As a matter of fact, the phase separation was visually evident also in the fully cured specimens of this formulation. However, had the phase separation been perfect, each peak would have coincided to its constituting part (KF-DVS or KF-HDDA). The two relaxation temperatures of the DVS-HDDA 1-1 final material suggest that one phase is practically KF-HDDA. As can be seen in Figure 5, the lower $T_{g f}$ of DVS-HDDA 1-1 is virtually equal to the $T_{g f}$ of DVS-HDDA 0-1 (neat KF-HDDA). On the other hand, the higher $T_{g}$ phase is predominantly KF-DVS with a small content of KF-HDDA. This causes the second $T_{g f}$ to decrease slightly from the $T_{g f}$ of DVS-HDDA 1-0 (neat KF-DVS). Noticeably, the $T_{g}$ of the lower $T_{g}$ phase does not increase upon the second stage reaction, indicating that this phase might contain a fraction of unreacted HDDA or KF monomers. The DVS-HDDA 3-1 intermediate material also exhibited two $E^{\prime \prime}$ peaks, the lower being less evident. Notably, the intermediate DVS-HDDA 1-1 and DVS-HDDA 3-1 materials have similar relaxation temperatures. Again, this is due to the phase separation. Upon stage 2 curing of the DVS-HDDA 3-1 material, the relaxation temperature increased significantly (up to ca. $120^{\circ} \mathrm{C}$ ) and the relaxation profile became apparently unimodal (Figure 5, bottom graph). However, the fully cured material was opaque, suggesting there was some phase separation. If the lower $T_{g}$ (associated to the phase rich in KF-HDDA network) had produced a E" peak with sufficient intensity to allow measurement, this would also allow the calculation of an average $T_{g}$ for the DVS-HDDA 3-1 final material and it would lie significantly closer to the Fox curve. In some materials, the $T_{g}$ determination of the KF-HDDA rich phase was not as precise as in others due to the complex behavior of $E^{\prime \prime}$ and $\tan \delta$. These required cross-referencing of $E^{\prime \prime}$ peaks with $E^{\prime}$ drops, since some of the $E^{\prime \prime}$ peaks were not accompanied by any significant drop in $E^{\prime}$ and therefore had to be discarded.

In order to elucidate the morphology of the fully-cured materials, ESEM was performed on the fractured surfaces of the specimens of different formulations. The results of the analysis are shown in Figure 6. Given the results from the DMA analysis, the phase separation should be more evident in DVS-HDDA 1-1. This hypothesis was confirmed by ESEM analysis shown in Figure 6a. The KF-HDDA (interior) phase seems to be sandwiched between the two layers of KF-DVS (exterior) network. It is hypothesized that upon stage 1 curing, an incompatible KF-DVS polymeric phase came about in which a small content of uncured HDDA was trapped. For both the intermediate and final DVS-HDDA 1-1 
materials, this HDDA content caused the higher of the two $T_{g}$ to deviate from a pure KF-DVS network. (See Figure 3, blue curves; and Figure 5). SEM pictures evidenced a strong incompatibilization between the HDDA-rich and DVS-rich phases.
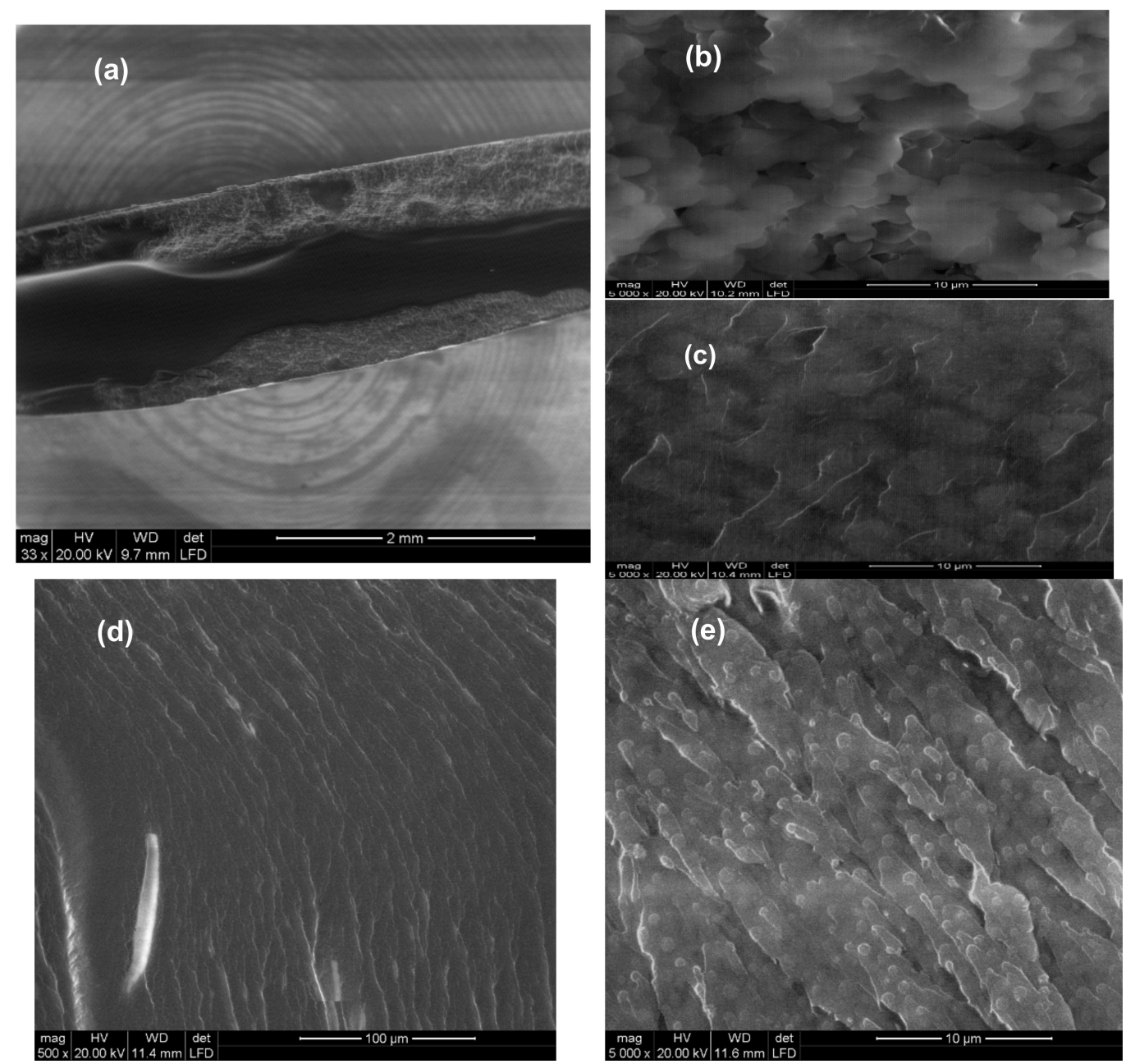

Figure 6. SEM images of final stage materials at low and high magnifications (left and right-hand side images, respectively). At the millimeter scale, the DVS-HDDA 1-1 material exhibits a dramatic phase separation (a) with a darker and denser interior phase (b) and a porous exterior phase with a lighter color (c). The DVS-HDDA 3-1 material appears more homogeneous at a scale of 100 microns (d). Further magnification reveals the disperse formation of spheres (prominently composed of the KF-HDDA phase) within the continuous KF-DVS phase (e).

However, the ESEM images of DVS-HDDA 3-1 suggest no such incompatibilization (Figure 6b, left-hand side). An acrylate-rich phase seems to have developed in the form of spheres which are covalently bound to the continuous KF-DVS matrix (Figure $6 \mathrm{~b}$ right-hand side images). As further confirmation, another formulation was prepared with a KF:DVS:HDDA molar ratio of 1:0.88:0.12 (formulation coded as DVS-HDDA 7-1), its $T_{g}$ was measured in DMA, and its ESEM images taken. The number of phase-separated spheres decreased with decreasing HDDA content, confirming the above hypothesis (See Figure S1 in Supporting Information). It is argued that this particular structure would impart improved toughness to the final material as long as the amount of the KF-HDDA phase is limited to avoid massive incompatibilization as was the case in DVS-HDDA 1-1 [32]. As can be seen in Figure $6 b$, the sizes of these covalently bound spheres might be sufficiently large to attenuate or even stop crack propagation. In this way, the impact energy can be dissipated. 


\subsection{Thermal Degradation of Materials}

In Figure 7, the TGA curves of the final materials are given together with the degradation rates (inset). When DVS-HDDA 1-0 and DVS-HDDA 0-1 are compared, the early onset of degradation of the latter material can be appreciated. This can be explained by its lower crosslinking density (recall that the functionality of both Michael acceptors DVS and HDDA are the same, but HDDA is a larger molecule with a long aliphatic chain). However, there is no clear explanation for the thermal degradation profiles of the dual materials used in this study. As per the authors' ongoing discussion about the distinct structure of these dual materials, the two constitutent networks are covalently interacting. This complicates the dissection of their individual effects on the thermal degradation behavior. Noticeably, the degradation of DVS-HDDA-1-1 starts earlier, suggesting the presence of unreacted monomers in the fully cured material, as suggested by the previous analysis of the $T_{g}$ of intermediate and the final materials. This could be due to the strong incompatibilization between HDDA-rich and DVS-rich phases. Nevertheless, the char yields clearly show an increasing trend, with increasing DVS content (the plateau above $450{ }^{\circ} \mathrm{C}$ ).

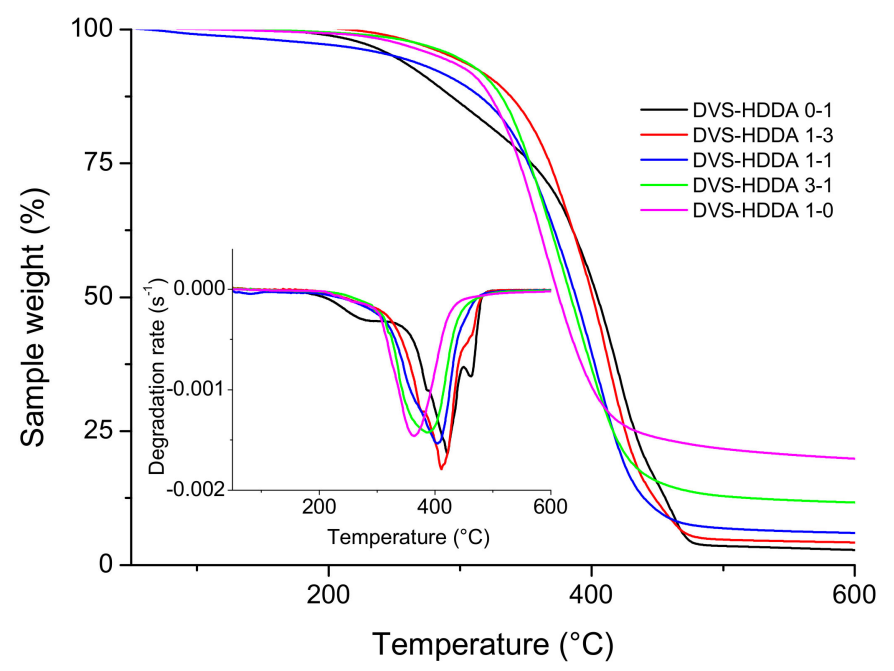

Figure 7. Thermogravimetric analysis (TGA) weight loss curves and the thermal degradation rates (inset) of the final stage materials.

\section{Conclusions}

A set of dual curable multiacetoacetate-multiacrylate-divinyl sulfone ternary formulations were prepared which attained a wide range of physical and thermomechanical properties. The curing process is truly sequential due to the significant difference between the reaction rates of the two curing stages. The first curing stage was a Michael addition of a proton donating multiacetoacetate to a divinyl sulfone. The kinetics of this relatively less studied Michael addition pair was analyzed and it was confirmed that both acetoacetate hydrogens were able to react at a moderate temperature and rate. The densely crosslinked first stage multiacetoacetate-divinyl sulfone polymer network gave the final materials high rigidity, whereas the second stage multiacetoacetate-diacrylate second stage networks introduced flexibility. The dual materials exhibited phase separation due to the incompatibility of the two polymer networks at compositions with the DVS molar ratios equal to or higher than $50 \%$. Nevertheless, the final material with $75 \%$ molar ratio of acetoacetate-divinyl sulfone developed a desirable microstructure, with a $T_{g}$ comparable to its neat counterpart. As further research, a formal comparison of these novel materials with epoxy and/or acrylate based thermosets with respect to thermomechanical and tensile properties could be undertaken. 
Supplementary Materials: The following are available online at http://www.mdpi.com/2073-4360/11/9/1408/s1, Figure S1: SEM images of DVS-HDDA 7-1 final material.

Author Contributions: Conceptualization, X.F.-F. and X.R.; methodology, O.K., X.F.-F., X.R., and À.S.; investigation O.K. and À.S.; formal analysis, O.K., X.F.-F., X.R., and À.S.; writing-original draft preparation, O.K.; writing-review and editing, O.K., X.F.-F., X.R., and À.S.; supervision, X.F.-F., X.R. and À.S.; project administration, X.R.; funding acquisition, X.R.

Acknowledgments: The authors thank King Industries, Inc. for their courtesy in supplying K-FLEX ${ }^{\circledR} 7301$. They also thank MCIU (Ministerio de Ciencia, Innovación y Universidades) and FEDER (Fondo Europeo de Desarrollo Regional) (MAT2017-82849-C2-1-R and MAT2017-82849-C2-2-R) and Generalitat de Catalunya (2017-SGR-77 and Serra Húnter program) for the financial support.

Conflicts of Interest: The authors declare no conflicts of interest.

\section{References}

1. Ramis, X.; Fernández-Francos, X.; De La Flor, S.; Ferrando, F.; Serra, À. Click-based dual-curing thermosets and their applications. In Thermosets 2 nd edition: Structure, Properties and Application; Guo, Q., Ed.; Elsevier: Amsterdam, The Netherlands, 2017; ISBN 9780081010280.

2. Konuray, O.; Fernández-Francos, X.; Ramis, X.; Serra, À. State of the Art in Dual-Curing Acrylate Systems. Polymers (Basel). 2018, 10, 178. [CrossRef] [PubMed]

3. Nair, D.P.; Cramer, N.B.; Gaipa, J.C.; McBride, M.K.; Matherly, E.M.; McLeod, R.R.; Shandas, R.; Bowman, C.N. Two-Stage Reactive Polymer Network Forming Systems. Adv. Funct. Mater. 2012, 22, 1502-1510. [CrossRef]

4. Retailleau, M.; Ibrahim, A.; Croutxé-Barghorn, C.; Allonas, X.; Ley, C.; Le Nouen, D. One-Pot Three-Step Polymerization System Using Double Click Michael Addition and Radical Photopolymerization. ACS Macro Lett. 2015, 4, 1327-1331. [CrossRef]

5. Peng, H.; Nair, D.P.; Kowalski, B.A.; Xi, W.; Gong, T.; Wang, C.; Cole, M.; Cramer, N.B.; Xie, X.; McLeod, R.R.; et al. High performance graded rainbow holograms via two-stage sequential orthogonal thiol-click chemistry. Macromolecules 2014, 47, 2306-2315. [CrossRef]

6. Konuray, O.; Areny, N.; Morancho, J.M.; Fernández-Francos, X.; Serra, À.; Ramis, X. Preparation and characterization of dual-curable off-stoichiometric amine-epoxy thermosets with latent reactivity. Polymer (Guildf). 2018, 146, 42-52. [CrossRef]

7. Kolb, H.C.; Finn, M.G.; Sharpless, K.B. Click Chemistry: Diverse Chemical Function from a Few Good Reactions. Angew. Chemie - Int. Ed. 2001, 40, 2004-2021. [CrossRef]

8. Binder, W.H.; Sachsenhofer, R. "Click" chemistry in polymer and material science: An Update. Macromol. Rapid Commun. 2008, 29, 952-981. [CrossRef]

9. Tunca, U. Orthogonal multiple click reactions in synthetic polymer chemistry. J. Polym. Sci. Part A Polym. Chem. 2014, 52, 3147-3165. [CrossRef]

10. Mather, B.D.; Viswanathan, K.; Miller, K.M.; Long, T.E. Michael addition reactions in macromolecular design for emerging technologies. Prog. Polym. Sci. 2006, 31, 487-531. [CrossRef]

11. Konuray, A.O.; Fernández-Francos, X.; Ramis, X. Curing kinetics and characterization of dual-curable thiol-acrylate-epoxy thermosets with latent reactivity. React. Funct. Polym. 2018, 122, 60-67. [CrossRef]

12. Chatani, S.; Wang, C.; Podgórski, M.; Bowman, C.N. Triple Shape Memory Materials Incorporating Two Distinct Polymer Networks Formed by Selective Thiol-Michael Addition Reactions. Macromolecules 2014, 47, 4949-4954. [CrossRef]

13. Peng, H.; Wang, C.; Xi, W.; Kowalski, B.A.; Gong, T.; Xie, X.; Wang, W.; Nair, D.P.; McLeod, R.R.; Bowman, C.N. Facile image patterning via sequential thiol-Michael/thiol-yne click reactions. Chem. Mater. 2014, 26, 6819-6826. [CrossRef]

14. Jin, K.; Wilmot, N.; Heath, W.H.; Torkelson, J.M. Phase-Separated Thiol-Epoxy-Acrylate Hybrid Polymer Networks with Controlled Cross-Link Density Synthesized by Simultaneous Thiol-Acrylate and Thiol-Epoxy Click Reactions. Macromolecules 2016, 49, 4115-4123. [CrossRef]

15. Konuray, A.O.; Fernández-Francos, X.; Serra, À.; Ramis, X. Sequential curing of amine-acrylate-methacrylate mixtures based on selective aza-Michael addition followed by radical photopolymerization. Eur. Polym. J. 2016, 84, 256-267. [CrossRef] 
16. González, G.; Fernández-Francos, X.; Serra, À.; Sangermano, M.; Ramis, X. Environmentally-friendly processing of thermosets by two-stage sequential aza-Michael addition and free-radical polymerization of amine-acrylate mixtures. Polym. Chem. 2015, 6, 6987-6997. [CrossRef]

17. Retailleau, M.; Pierrel, J.; Ibrahim, A.; Croutxé-Barghorn, C.; Allonas, X. Sequenced click chemistry and photopolymerization: a new approach toward semi-interpenetrating polymer networks. Polym. Adv. Technol. 2017, 28, 491-495. [CrossRef]

18. Konuray, A.O.; Liendo, F.; Fernández-Francos, X.; Serra, À.; Sangermano, M.; Ramis, X. Sequential curing of thiol-acetoacetate-acrylate thermosets by latent Michael addition reactions. Polymer (Guildf). 2017, 113, 193-199. [CrossRef]

19. Konuray, A.O.; Ruiz, A.; Morancho, J.M.; Salla, J.M.; Fernández-Francos, X.; Serra, À.; Ramis, X. Sequential dual curing by selective Michael addition and free radical polymerization of acetoacetate-acrylate-methacrylate mixtures. Eur. Polym. J. 2018, 98, 39-46. [CrossRef]

20. Moszner, N.; Rheinberger, V. Reaction behaviour of monomeric $\beta$-ketoesters, 4. Polymer network formation by Michael reaction of multifunctional acetoacetates with multifunctional acrylates. Macromol. Rapid Commun. 1995, 16, 135-138.

21. Kim, Y.B.; Kim, H.K.; Nishida, H.; Endo, T. Synthesis and characterization of hyperbranched poly( $\beta$-ketoester) by the Michael addition. Macromol. Mater. Eng. 2004, 289, 923-926. [CrossRef]

22. Williams, S.R.; Miller, K.M.; Long, T.E. Michael addition reaction kinetics of acetoacetates and acrylates for the formation of polymeric networks. Prog. React. Kinet. Mech. 2007, 32, 165-194. [CrossRef]

23. Podgórski, M.; Chatani, S.; Bowman, C.N. Development of glassy step-growth thiol-vinyl sulfone polymer networks. Macromol. Rapid Commun. 2014, 35, 1497-1502. [CrossRef]

24. Chatani, S.; Nair, D.P.; Bowman, C.N. Relative reactivity and selectivity of vinyl sulfones and acrylates towards the thiol-Michael addition reaction and polymerization. Polym. Chem. 2013, 4, 1048-1055. [CrossRef]

25. Chatani, S.; Sheridan, R.J.; Podgórski, M.; Nair, D.P.; Bowman, C.N. Temporal control of thiol-click chemistry. Chem. Mater. 2013, 25, 3897-3901. [CrossRef]

26. Venditti, R.A.; Gillham, J.K. A relationship between the glass transition temperature (Tg) and fractional conversion for thermosetting systems. J. Appl. Polym. Sci. 1997, 64, 3-14. [CrossRef]

27. Jian, Y.; He, Y.; Sun, Y.; Yang, H.; Yang, W.; Nie, J. Thiol-epoxy/thiol-acrylate hybrid materials synthesized by photopolymerization. J. Mater. Chem. C 2013, 1, 4481-4489. [CrossRef]

28. Kaya, N.U.; Onen, A.; Guvenilir, Y. Photopolymerization of acrylates by enzymatically synthesized PCL based macrophotoinitiator. Express Polym. Lett. 2017, 11, 493-503. [CrossRef]

29. Lantean, S.; Roppolo, I.; Sangermano, M.; Fabrizio Pirri, C.; Chiappone, A. Development of New Hybrid Acrylic/Epoxy DLP-3D Printable Materials. Innovations 2018, 3, 29. [CrossRef]

30. Sangermano, M.; Carbonaro, W.; Malucelli, G.; Priola, A. UV-cured interpenetrating acrylic-epoxy polymer networks: Preparation and characterization. Macromol. Mater. Eng. 2008, 293, 515-520. [CrossRef]

31. Fox, G.T. Influence of diluent and of copolymer composition on the glass temperature of a polymer system. Bull. Am. Phs. Soc. 1952, 1, 123.

32. Flores, M.; Fernández-Francos, X.; Ferrando, F.; Ramis, X.; Serra, À. Efficient impact resistance improvement of epoxy/anhydride thermosets by adding hyperbranched polyesters partially modified with undecenoyl chains. Polymer (Guildf). 2012, 53, 5232-5241. [CrossRef]

(C) 2019 by the authors. Licensee MDPI, Basel, Switzerland. This article is an open access article distributed under the terms and conditions of the Creative Commons Attribution (CC BY) license (http://creativecommons.org/licenses/by/4.0/). 